\title{
"INFINIDADES IMANENTES": AFINIDADES ENTRE A OBRA DE ARTE E O ORGANISMO EM V. JANKÉLÉVITCH, LEITOR DE BERGSON
}

("Immanent infinities": resemblances between the work of art and the organism in V. Jankélévitch, reader of Bergson)

\section{Clovis Salgado Gontijo Oliveira*}

Resumo: A existência de parentesco estrutural entre o organismo e a obra de arte é pensada desde a Poética de Aristóteles. Esta hipótese repete-se no pensamento contemporâneo, como, por exemplo, no estudo Bergson (1931), de Vladimir Jankélévitch. Este ensaio tem, como principal objetivo, examinar quais aspectos presentes no referido estudo garantem uma aproximação entre as esferas orgânica e artística. Num segundo momento, verificaremos em que pontos estas eventualmente se distanciam. Além disso, analisaremos se a relação entre arte e vida, percebida por Jankélévitch em sua leitura de Bergson, possui alguma repercussão na estética jankélévitchiana.

Palavras-chaves: Vida, organismo, mecanismo, obra de arte, música.

Abstract: The presence of a structural bond between the organism and the work of art is already considered by Aristotle's Poetics. This hypothesis reappears in contemporary thought, as we can notice in V. Jankélévitch's study Bergson (1931). This essay intends to examine which aspects, cited in the aforementioned study,

\footnotetext{
* Bacharel (Faculdade Santa Marcelina, São Paulo) e Mestre (Texas Christian University, Fort Worth, EUA) em Música. Bacharel em Filosofia (FAJE, BH) e Doutorando em Filosofia com menção em Estética e Teoria da Arte pela Faculdade de Artes da Universidade do Chile. Bolsista de doutorado Conicyt ("Comisión Nacional de Investigación Científica e Tecnológica"). Artigo submetido a avaliação no dia 09/09/2010 e aprovado para publicação no dia 15/05/2011.
} 
provide a possible approach between the organic and the artistic. It will be also verified in which points those two spheres may eventually differ from each other. Furthermore, it will be analyzed to what extent the connection between life and art, observed by Jankélévitch in his reading of Bergson, may have influenced jankélévitchian aesthetics.

Key-words: Life, organism, mechanism, work of art, music.

\section{1) Introdução}

$\mathrm{Q}$ uanto à narrativa mimética e em metros, é evidente que se deve com por, assim como nas tragédias e histórias ( $m$ thoi) dramáticas, sobre uma única (mia) ação (práxis) inteira (holê) e completa (teleia), que tenha começo, meio e fim, para que, como um único (hen) e inteiro (holos) ser vivo (zóion), produza o prazer que lhe é próprio; e [é evidente] que não deve ser semelhante às composições das narrativas historiográficas, nas quais é necessário fazer não a exibição de uma única ação, mas de um único período de tempo $(\ldots)^{1}$

Esta clássica passagem da Poética de Aristóteles revela-nos que, já para a filosofia antiga, o organismo se apresenta como imagem capaz de aproximar-nos a uma compreensão da obra de arte. Esta aproximação seria possível graças à descoberta de um parentesco estrutural entre o orgânico e o artístico. No contexto da Poética, a obra de arte, mais especificamente a epopeia, possui existência semelhante à do "organismo vivo", ou seja, completa, unificada e inscrita numa duração temporal finita.

Também a filosofia contemporânea estabelece nítida correspondência entre as esferas da vida e da arte. Na primeira obra publicada de Vladimir Jankélévitch, um estudo sobre o pensamento de Bergson [Bergson, 1931], esta tese aristotélica repete-se e desenvolve-se. Mas enquanto, na Poética, a imagem do organismo nos aproxima à arte, em Bergson, é geralmente a arte que nos acerca ao organismo. Esta variação de abordagem deve-se aos diferentes focos de cada obra. Se na Poética, as questões examinadas são de natureza estética, em Bergson, elas referem-se primordialmente à vida - e, na maioria dos casos, à vida humana.

Este ensaio propõe-se a identificar e analisar os principais pontos de contato, presentes no estudo Bergson, entre a esfera artística - representada pela obra de arte, pelo processo artístico e pela atitude do artista - e a vida. Embora a obra que nos serve como base para este artigo se dedique inteiramente ao pensamento de Bergson, não a cotejaremos com as obras deste filósofo.

${ }^{1}$ ARISTÓTELES. Poética. Capítulo XXIII. 1459 a 17. Tradução Luiza Dutra. 
Esta opção metodológica deve-se não apenas à necessidade de delimitar nosso objeto de estudo, tendo em vista a finalidade a que aqui nos dedicamos, mas também por este trabalho haver surgido dentro de uma pesquisa mais ampla sobre o pensamento do filósofo e musicólogo de origem russa. Deste modo, nosso principal interesse não seria realizar uma interpretação da obra bergsoniana, mas sim examinar a leitura efetuada por Jankélévitch da filosofia de seu mestre, leitura esta que influencia e fundamenta algumas ideias recorrentes em sua reflexão estética.

É importante ressaltar, nesta introdução, que a estrutura deste trabalho, dividido em tópicos e temas, é algo artificial. As características comuns ao organismo e à obra de arte, que abrangem grande parte deste artigo, não se prestariam a uma dissociação. Elas se autoimplicam dentro de ambas as esferas, que, como veremos, não deveriam comportar divisões.

\section{2) Semelhanças entre o organismo e a obra de arte}

\section{1) Totalidade das partes}

O universo da vida é, ao contrário, necessariamente um universo de indivíduos, de totalidades "insulares" e, no sentido próprio da palavra, de obrasprimas que, como os inteligíveis de Plotino, expressam cada uma o conjunto completo do mundo do qual parecem fazer parte. ${ }^{2}$

Nesta passagem, extraída das primeiras páginas da obra Bergson, Jankélévitch estabelece inegável identificação entre as esferas da vida e da obra de arte. Tal identificação deve-se, neste contexto, a dois principais fatores. Em primeiro lugar, os exemplares de ambas as esferas são "seres" individuais, singulares. Além disso, como já havia sido colocado pela Poética, cada um deles expressa uma totalidade.

Este segundo elemento aparece, no estudo Bergson, como um dos pontoschave para a diferenciação entre organismos e mecanismos. Será necessário verificar, primeiramente, como esta distinção pela totalidade é concebida, para, num segundo momento, examinar de que modo a obra de arte se afasta do mecanismo e se aproxima da dinâmica do organismo.

Seguindo a concepção herdada da Monadologia (\$64) de Leibniz, Bergson concebe os mecanismos como simples máquinas, compostas de peças que, isoladas, são incapazes de expressar o todo. Uma peça de um mecanismo

\footnotetext{
2 JANKÉLÉVITCH, V. Bergson. p. 7-8.
} 
não nos "informa" necessariamente algo sobre as demais peças às quais será conectada nem sobre a máquina cuja estrutura há de integrar. Deste modo, verifica-se, nos mecanismos, uma nítida oposição e descontinuidade entre o parcial e o todo.

Contudo, esta distinção não se aplica aos organismos, cujas "partes" sempre expressam uma totalidade. Como explica Jankélévitch, as células orgânicas, ao contrário das peças mecânicas, "são verdadeiros microcosmos, entidades autônomas embora reflitam, como diria Leibniz, o universo inteiro imanentemente" ${ }^{3}$

Esta ideia, presente em Leibniz, reaparece em Schopenhauer, dentro de um novo contexto, agora transferida para a relação entre as espécies e a natureza como um todo. De acordo com $O$ mundo como vontade e representação (\$28), a totalidade reside em cada uma das espécies encontradas na natureza. Se estas se apresentam com grande diversidade, isto ocorre porque cada uma delas enfatiza um aspecto particular do todo:

As diferentes espécies, diz Schopenhauer, manifestam-se como diversas variações sobre o tema da coisa em si, mas, em cada variação, o tema encontra-se todo inteiro: como diria Leibniz, apenas a perspectiva se modifica. $\mathrm{Na}$ planta, por exemplo, repousa algo como a esperança da mobilidade animal, mas o enfoque está sobre a vida vegetativa; no animal subsiste algo como uma lembrança da vida vegetativa, mas o enfoque está sobre a sensibilidade e a consciência. ${ }^{4}$

É curioso notar que um gênero musical seja utilizado por Schopenhauer para ilustrar a totalidade que caracteriza a vida. No entanto, segundo Jankélévitch, a presença do todo na parte não é exclusiva de um procedimento composicional específico como o "tema com variações", em que cada variação (parte) contém o tema (todo), ou ao menos mantém alguns de seus aspectos estruturais. A melodia de todas as obras musicais de construção melódica que se aproximam da dinâmica da vida - e, assim, da inefabilidade, na perspectiva jankélévitchiana -, repousaria em cada uma das "células" que a compõem..$^{5}$ A mesma dinâmica repete-se no plano verbal, nos chamados "textos espirituais", que, ao contrário dos "textos materiais", estariam construídos em consonância com os organismos. Cada uma das palavras ou das passagens dos "textos espirituais" expressaria uma pequena totalidade.

${ }^{3}$ Idem. p. 21

${ }^{4}$ Idem. p. 209.

5 "Quando reconstruo a melodia a partir das notas, faço-o por já conhecer a melodia, e por, em cada nota, ela se encontrar adormecida (elle sommeille), invisível e latente; caso contrário não reencontraria o canto a não ser por um maravilhoso acaso mil vezes renovado" [Idem, 32]. 
As coisas espirituais são, portanto, sempre inteiras: esta é a razão pela qual, sem dúvida, a fragmentos de matéria não correspondem absolutamente fragmentos de vida, assim como a pedaços de frases não correspondem absolutamente pedaços de ideia. E já é possível prever que entre estes dois textos tão dessemelhantes: o texto espiritual de que todo o fragmento é total, o texto material de que todo o fragmento é fragmentário, não se possa conceber nenhum paralelismo literal, nenhuma transposição justalinear. O poema está sempre para além de seu próprio texto. ${ }^{6}$

A compreensão das "coisas espirituais" como realidades totais, completas e inteiras dariam margem a uma possível distinção entre o organismo e a obra de arte. O primeiro "nasce pequeno, mas inteiro" ${ }^{7}$, uma vez que "as coisas da vida estão fora da categoria do crescimento e da diminuição, não são suscetíveis nem de mais nem de menos, mas somente de modificações" ${ }^{8}{ }^{8}$ Ao contrário, a obra de arte parece, à primeira vista, não nascer inteira, aproximando-se assim às coisas fabricadas, cuja totalidade é apenas alcançada ao final de um processo. Nesta perspectiva, a produção artística identifica-se com o assim chamado "trabalho-rendimento", isto é, com uma produção que se realiza a partir da acumulação progressiva de dados ou materiais. ${ }^{9}$

No entanto, alguns elementos já examinados neste ensaio nos mostram que esta identificação é inadequada não apenas quando transferida ao âmbito da vida - concebida, neste caso, como realidade criada demiurgicamente , mas também quando aplicada ao plano artístico. Se uma única nota ou palavra de um poema é compreendida como microcosmos capaz de conter a totalidade da melodia ou do verso, poderíamos pensar que, junto às primeiras notas esboçadas sobre o pentagrama, toda a obra estaria de algum modo presente. Assim, a obra de arte também nasceria, à sua maneira, "pequena, mas inteira".

\section{2) Irredutibilidade ao modelo "ato e potência"}

Entretanto, é importante destacar que a compreensão do organismo - ou da obra de arte - como realidade inteira desde sua gênese não deve ser interpretada por meio do modelo "ato" e "potência". Dizer que o organismo nasce inteiro não significa exatamente que sua "inteireza" e "totalidade" estejam nele presentes de modo potencial. Isto porque, como nos mostra

\footnotetext{
${ }^{6}$ JANKÉLÉVITCH, V. Bergson. p. 10.

${ }^{7}$ Idem. p. 261.

${ }^{8}$ Idem. p. 262.

9 Jankélévitch descreve do seguinte modo a imagem do "trabalho-rendimento": "quanto mais os pedreiros trabalham, mais a casa se levanta; quanto mais o copista escreve, mais a cópia se alonga: o trabalho fabricador é o único no qual a amplificação do produto é quantitativa e espacialmente proporcional ao progresso da ação" [Idem. p. 257].
} 
Jankélévitch, costuma acompanhar à distinção "ato" e "potência" um preconceito metafísico, que admite uma variação na "quantidade de ser"10 de uma realidade, durante seu desenvolvimento. Se esta possui menor "quantidade" de ser quando é ainda mera possibilidade, se alcança sua "perfeição" (teleotes) somente ao final de um processo, como poderia ser pensada algo já inteiro desde seu estado inicial?

Além disso, o esquema "ato" e "potência", ao sugerir o desenvolvimento do organismo segundo um "plano" interno determinado, acaba por conferir um caráter previsível à vida. Segundo Jankélévitch, leitor de Bergson, uma das particularidades mais essenciais do vital é justamente sua "imprevisibilidade". Diferentemente da máquina, que obedece a uma orientação pré-estabelecida, o organismo, submergido na duração e constantemente reconfigurado, é capaz de gerar "frutos" insuspeitados.

Um mecanismo não comporta nenhum "para além", e a enumeração de suas partes esgota literalmente toda a sua realidade. Uma máquina perfeita nunca gera, a rigor, decepções, mas, do mesmo modo, nunca produz surpresas. Não possui falhas, mas tampouco os milagres que são, de algum modo, a marca da vida. Uma máquina perfeita proporciona tudo o que nos promete, sua realidade óptica é capaz de nos oferecer tudo o que nossa inteligência tem direito de esperar dela, mas sabemos que será em vão lhe pedir algo mais. Um mecanismo não deixa nada para se adivinhar, pressentir e buscar. Ele não cria novas soluções. Não é inventivo. Há situações para as quais está feito, outras para as quais não está: isso é tudo. A eloquência da vida, ao contrário, é feita, sobretudo, de reticências. Quando a vida está em alguma parte, sentimos de modo confuso que tudo se torna possível. Os organismos são profundos: estão, por assim dizer, para além de si mesmos; ou melhor, eles são o que não são, são bem mais que eles mesmos. ${ }^{11}$

É importante notar que o organismo a que se refere Jankélévitch não equivale a um organismo qualquer. A fim de escapar da programação de um manual ou de uma semente, é necessário vivenciar não só duração, mas também a liberdade. Assim, no contexto da passagem citada, os termos "organismo" e "vida" dizem respeito, especificamente, à esfera humana.

Contudo, a vida humana não é a única realidade dotada de natureza imprevisível. Também no processo de elaboração de uma obra de arte igualmente inscrita na categoria das "realidades espirituais" 12 - verificamse surpresas, mudanças, "desvios". Estes fatores poderiam atuar de modo negativo sobre a obra: ao ser "concretizada", a intenção inicial corre o risco de perder sua originalidade, contaminando-se de fórmulas convencionais e preestabelecidas. Por outro lado, o exercício artístico, realizado no tempo

${ }^{10}$ Idem. p. 276.

${ }^{11}$ Idem. p. 12.

${ }^{12}$ Idem. p. 7. 
e povoado de múltiplas eventualidades e tentativas, oferece ao artista a oportunidade de descobrir, seguindo a terminologia de La musique et l'ineffable, "belezas imprevistas"..$^{13}$ A contribuição positiva do "caminho" poético sobre a produção do artista também aparece no estudo sobre Bergson, num contexto que reafirma o parentesco entre a arte - neste caso, a música - e a vida, compreendida como a interioridade humana:

O músico sabe sempre em qual direção encontrará o poema sobre o qual medita e cujos temas já flutuam na sua imaginação, mas ele não suspeita todos os encontros que fará ao longo de sua rota, as aventuras maravilhosas e encantadoras que seu próprio gênio lhe prepara. A essência da improvisação consiste justamente, a nosso ver, a lançar-se sem reserva a essas aventuras da criação musical. O improvisador dirige-se à descoberta de si mesmo e para isso dá crédito a esses recursos imprevistos, a essas surpresas milagrosas que nosso espírito nos reserva de maneira inesgotável. O que poderíamos esperar de nós mesmos? ${ }^{14}$

A valorização da improvisação musical por Jankélévitch aponta para um aspecto que também sugere a inadequação do modelo "ato" e "potência" à esfera dos organismos e das obras de arte. Neste modelo, verifica-se uma perspectiva teleológica que hierarquiza as diferentes etapas percorridas pelas "coisas espirituais". Dentro desta, seria conferido ao organismo maior valor - ou, seguindo o preconceito constatado por Jankélévitch, maior "quantidade de ser" - quando este alcança sua maturidade e encontra-se apto para a produção e a reprodução. Quanto à obra, seu ápice estaria em seu estado final, no momento em que se completa (e, no caso da obra a ser interpretada, quando pode ser, analogamente ao ser vivo, reproduzida).

A improvisação contrasta radicalmente com este modelo, já que se realiza de maneira mais livre, sem orientar-se a uma tonalidade ou a um tema "previsível" e predeterminado, como costuma ocorrer em composições musicais baseadas em arcabouços formais rigorosamente definidos (a sonata e a fuga, por exemplo). Assim, o valor concedido à atitude improvisatória expressa uma postura filosófica que não compreende um momento da vida de modo instrumentalizado, ou seja, como mero "recurso" necessário para a consecução de certa finalidade, localizada num momento mais fundamental. Para a "filosofia da duração", assim como para o improvisador musical, cada instante é equivalente em termos axiológicos. Sob esta perspectiva, nenhum momento poderia ser reduzido a um mero estado de espera.

\footnotetext{
13 "A matéria sonora não está, portanto, pura e simplesmente a mercê do espírito e à disposição de nossos caprichos: mas é recalcitrante e por vezes se recusa a conduzir-nos lá onde gostaríamos de ir; ou, melhor dito: este instrumento que é, tão frequentemente, um obstáculo nos conduz para além, em direção a uma beleza imprevista" [JANKÉLÉVITCH, V. La musique et l'ineffable. p. 39].

${ }^{14}$ JANKÉLÉVITCH, V. Bergson. p. 220.
} 
Ao contrário, uma visão teleológica que hierarquiza os momentos traz consigo uma desvalorização do processo, do desenvolvimento. Tal desvalorização poderia ser representada pela atitude do cientista que, dedicado à previsão astronômica (ou meteorológica), chega a "eliminar" o tempo intermediário entre seu presente e o momento futuro no qual tem "lugar" sua projeção. Por outro lado, a valorização do processo assemelha-se à postura do profeta. Este faz sua "adivinhação" respeitando a "absoluta posteridade" do futuro que profetiza, isto é, sem tentar antecipá-lo. O tempo que separa o profeta do evento profetizado é compreendido como necessário não só à realização, mas também ao "esclarecimento" e configuração da profecia.

Dentro da atitude profética está o artista, cuja obra, ao ser pela primeira vez "vislumbrada", não pode ser completamente "prevista":

Assim, a essência da inspiração artística é antecipar o esquema, jamais a existência; é um pressentimento que não exclui os acasos da criação, que deve contar com a realidade do tempo. ${ }^{15}$

Deste modo, a imprevisibilidade, a valorização do desenvolvimento e a inserção real na duração que impede o estabelecimento de uma hierarquia entre os momentos encontram-se autoimplicadas na compreensão bergsoniana (e também jankélévitchiana) da vida, da obra e do fazer artístico.

É interessante acrescentar que a esfera artística se afasta do esquema "ato" e "potência" tanto no âmbito da criação quanto no da interpretação. Se a poiesis é análoga à vida na medida em que não se identifica com uma "atualização", num sentido definido e predeterminado, de um elemento em germe, o ato interpretativo parece ressaltar, mais que o organismo, a inadequação da aplicação do par "ato" e "potência" ao espiritual. Apesar de Jankélévitch não abordar este aspecto de modo explícito no seu estudo sobre Bergson, é possível inferi-lo por meio de algumas ideias presentes em sua "estética do inefável".

A inefabilidade artística, que se revela simultaneamente como impossibilidade de definição verbal da arte e como impossibilidade de determinação do conteúdo expressivo de uma obra artística, não poderia deixar de influir sobre a interpretação. Ao revelar-se, sob o ponto de vista da expressividade, como equívoca, ambígua, repleta de reticências, uma obra artística - especialmente uma obra musical, no caso da estética jankélévitchiana - poderia ser interpretada em "direções" múltiplas. Assim, à fecundidade indeterminada do inefável corresponderia a possibili-

${ }^{15}$ Idem. p. 219. 
dade de infinitas interpretações. Neste sentido, a obra interpretada nunca seria "atualizada" de modo definitivo. Ao realizar-se como algo constantemente novo, vinculado ao presente e aos encadeamentos sempre singulares constituídos pela experiência da temporalidade, a obra de arte interpretada não pode ser compreendida como mera réplica de um modelo preestabelecido e se apresenta como uma espécie de organismo inexistente na natureza, devido ao seu inesgotável poder de renovação.

\section{3) Continuidade e superposição}

Além da totalidade e da irredutibilidade ao modelo "ato e potência", os organismos distinguem-se dos mecanismos por um terceiro aspecto, que também se encontra presente na obra de arte. Enquanto nas realidades materiais, ou seja, nos mecanismos, os "estados sucessivos permanecerão exteriores um ao outro sem que nenhuma transição, por mais insensível que seja, consiga solicitar o antigo no novo"16, as realidades espirituais caracterizam-se por uma continuidade e superposição das experiências. Segundo Jankélévitch, estas duas características da esfera da vida correspondem, respectivamente, a duas modalidades de imanência: a "imanência de sucessão" e a de "coexistência".

Graças à imersão do organismo (e mais especificamente do ser humano) na duração e à atuação da memória, as experiências "encadeiam-se" umas às outras, acumulam-se, "amalgamam-se", "perpetuam-se", possibilitando, assim, a primeira modalidade de imanência. Não obstante, a mera sucessão "não seria suficiente para diferenciar irredutivelmente os organismos e os mecanismos". ${ }^{17}$ A acumulação, o entrelaçamento e a continuidade das experiências pressupõem que elas "coexistam" na realidade espiritual.

Deste modo, identificamos o segundo aspecto citado, a "imanência de coexistência", que permite aos organismos manifestar, a cada instante, a totalidade do vivido. Esta "manifestação", ou "reconstituição" da totalidade não significa uma "epifania" constante de todas as experiências passadas. Como nos mostra Jankélévitch, no âmbito do espiritual haverá sempre uma "região" de subentendidos, de ambiguidades, de elementos que não se revelam por completo. No entanto, estes encontram-se implícitos na totalidade que nos constitui, resultante de nossa transformação pelas experiências e de nossas próprias elaborações sobre o que experimentamos. A cada momento, uma realidade espiritual realça determinado "conteúdo" já vivido ou descobre novas "combinações" entre experiências, que, amalgamadas em nossa totalidade, já não poderiam ser encontradas em seu "es-

\footnotetext{
${ }^{16}$ Idem. p. 5.

${ }^{17}$ Idem. p. 5.
} 
tado puro" e inicial. (Portanto, mesmo que os organismos manifestem a cada instante a totalidade, esta não se esgota numa única de suas "configurações".)

Se a "imanência de sucessão" pode ser igualmente evocada pelo teatro, pela poesia e pela música - expressões artísticas estruturadas a partir de um encadeamento temporal -, esta última revela-se como a mais adequa$\mathrm{da}^{18}$ para "representar" a "imanência de coexistência":

Esta imanência mútua, da qual nosso entendimento tem horror, nossas artes, ao contrário, procuram imitar. No entanto, nenhuma delas tem maior êxito que a música, sem dúvida porque esta, armada do contraponto, possui mais meios que qualquer outra arte de exprimir essa compenetração íntima dos estados de alma. Esta é a verdadeira missão da polifonia. ${ }^{19}$

Constatamos, por esta passagem, um primeiro aspecto capaz de relacionar a música à "imanência de coexistência". O território sonoro favorece, de modo particular, a integração harmoniosa e simultânea de diferentes vozes, temas e expressões - integração dificilmente obtida dentro do campo verbal. A simultaneidade unificada de vozes, "concordia discors", parece reproduzir a estrutura polifônica da própria interioridade humana, na qual se superpõem as mais variadas lembranças e disposições anímicas.

Além da polifonia, outro aspecto do âmbito sonoro permite associá-lo à "imanência de coexistência". Trata-se de um componente acústico: o som natural, por si mesmo, compõe-se da integração de variadas vibrações. Este aspecto é recordado por Jankélévitch, que a ele recorre para expressar a particular concepção evolutiva bergsoniana, denominada "evolução em feixe" ("évolution en gerbe"). Assim como o organismo humano é constituído por uma multiplicidade de conteúdos e estados de alma, que não só se sucedem, mas também coexistem, a evolução deve conciliar "por uma parte a duração e por outra uma pluralidade real de forças vivas". ${ }^{20} \mathrm{Um}$ modelo de "evolução retilínea", em que as espécies se sucedem de forma neutra, sem superposição, sem "imanência", é criticado por Jankélévitch na medida em que se assemelharia "a um som superficial e inteiramente puro no qual não vibraria nenhum desses harmônicos que lhe conferem todo o sabor". ${ }^{21}$

18 Apesar de Jankélévitch não abordar este tema, poderíamos aventar que as duas modalidades de imanência se encontrariam, em certa medida, presentes em toda obra interpretativa. Isso porque esta possui, como o organismo, uma espécie de "memória": a obra interpretada no presente está composta (e transformada) por uma continuidade de interpretações que se sucedem ao longo da história e que nela coexistem.

19 JANKÉLÉVITCH, V. Bergson. p. 6.

20 JANKÉLÉVITCH, V. Bergson. p. 211.

${ }^{21}$ Idem. p. 211. 
Deste modo, a música apresenta-se, para o discípulo de Bergson, como a arte mais próxima da esfera da vida: nela se realizam e se manifestam, por diferentes razões, as "propriedades" espirituais da continuidade e da superposição.

\section{4) Imersão na duração, não-espacialidade, caráter crepuscular}

A duração ("durée") pode ser compreendida como a condição de possibilidade da "infinidade imanente"22, ou seja, da inefabilidade das "coisas espirituais". Segundo Jankélévitch, "sem a duração, as coisas não seriam senão o que são"23, isto é, igualar-se-iam às máquinas, à esfera do material.

A participação fundamental da duração nas "realidades espirituais" pode ser comprovada pelos exemplos do inefável propostos por Jankélévitch em La musique et l'ineffable. Segundo o filósofo, a inefabilidade é experimentada na música, na vida, na liberdade, no mistério de Deus e no amor. Apesar de não examinar cada uma destas "experiências" nessa obra de ênfase musical, é possível afirmar que a inclusão do amor - e inclusive do mistério divino - na categoria do inefável deve-se a sua inserção essencial no tempo. ${ }^{24}$ Assim revela uma passagem do estudo sobre Bergson, em que Jankélévitch opõe duas concepções contrastantes sobre o amor. A primeira, defendida por seu mestre e também por Schopenhauer, concebe-o "na dimensão do tempo, como o veículo do esforço orientado à conquista do devir"25. Isto significa atrelar o amor ao desejo de permanência da espécie, permanência que se efetua num momento futuro. A segunda concepção, elaborada por Guyau, "considera o amor antes inscrito na atualidade do espaço, como o acordo perfeito de individualidades em consentimento". 26

\footnotetext{
${ }^{22}$ A expressão "infinidade imanente", que aparece no estudo Bergson [JANKÉLÉVITCH, V. Bergson. p. 13], foi escolhida como título para este ensaio por conter vários aspectos da compreensão bergsoniana da vida e também por conjugar dois dos principais "traços" do inefável jankélévitchiano.

${ }^{23}$ JANKÉLÉVITCH, V. Bergson. p. 5.

${ }^{24}$ É importante destacar que tanto a apreensão do mistério divino quanto a própria concepção da divindade aparecem em Jankélévitch diretamente vinculadas à questão temporal. No primeiro caso, a experiência de contato com o Absoluto realiza-se como uma espécie de "iluminação" (éclair), que transcorre num brevíssimo lapso de tempo. Esta ideia, presente em diversos relatos místicos, é retomada e elaborada pelo filósofo, que a transfere às experiências humanas mais fundamentais vivenciadas no plano da imanência. No segundo caso, Deus é pensado como "potência", como "motor dinâmico e a fortiori uma energia cinética" [JANKÉLÉVITCH, V. Le je-ne-sais-quoi et le presque-rien. v. I. La manière et l'occasion, 100], "puro fazer-ser sem ser, cuja existência inteira é operação contínua e nada senão operação" [Idem, 103].

${ }^{25}$ Idem. p. 212.

${ }^{26}$ Idem. p. 213.
} 
A inscrição essencial na duração, característica das experiências mais fecundas da vida, impede que estas sejam expressas tanto de modo verbal unívoco - impossibilidade implícita no conceito de inefável - quanto em termos matemáticos. Isto porque a própria duração que as constitui não pode ser medida, ou seja, reduzida a termos numéricos. Somente é possível medir quando se realiza uma superposição entre o que se mede e um modelo preestabelecido. No entanto, tal modelo, no caso da duração, não poderia ser o próprio tempo, uma vez que este, como fluxo contínuo, afasta-se de uma "regra" fixa de medida.

A palavra "regra" (régua, regula) sugere uma alternativa para a medição do tempo, utilizada de modo frequente pelas notações musicais. Frente à impossibilidade de superpor o tempo ao próprio tempo, costumamos medir a duração a partir de um parâmetro espacial. Segundo Bergson, este procedimento é inadequado, pois a duração e o espaço são duas "realidades metafisicamente distintas". ${ }^{27}$ A duração efetiva identifica-se com a imersão do espírito no presente, que não equivale a um "ponto" determinado, mas sim a uma mudança contínua. Assim, a duração não pode ser representada através de coordenadas espaciais e estáticas.

A impossibilidade de uma representação espacial da "duração" pode ser pensada a partir de um fenômeno natural: o pôr do sol. Como nos mostra Stuart Mill, este também não possui uma localização precisa, sendo impossível "fixar" sua ocorrência acima ou abaixo da linha do horizonte. ${ }^{28} \mathrm{~A}$ ambiguidade dos fenômenos que "radicalizam" a "imersão" no tempo demonstra, uma vez mais, o limite do sentido visual e do modelo epistemológico nele baseado.

Talvez seja este estado "não-localizável" e não-definido das realidades submetidas à "duração", juntamente com sua imprevisibilidade, o que permite a Jankélévitch pensar numa essência crepuscular ou noturna para o musical. Este estado "utópico" da arte sonora é confirmado em La musique et l'ineffable, no qual seu autor reafirma a impossibilidade de encontrar, num lugar preciso e determinado, alguns dos exemplos já citados do inefável, dentre os quais sobressai o fenômeno musical..$^{29}$

É interessante notar que, no estudo sobre Bergson, a indeterminação "residencial" da música ilustra justamente o caráter "não-localizável" da vida do espírito. Jankélévitch estabelece, nessa obra, uma curiosa analogia entre a alma e o fenômeno musical, por um lado, e o corpo e a materialidade acústica ou performativa, por outro:

Há certa correspondência, ou ao menos um sincronismo, entre as modificações moleculares do córtex e a sucessão das imagens: como poderíamos nos

27 JANKÉLÉVITCH, V. Bergson. p. 72.

${ }^{28}$ Idem. p. 95.

${ }^{29}$ Cf. JANKÉLÉVITCH, V. La musique et l'ineffable. p. 137-138. 
espantar que os gestos do regente de orquestra correspondam a cada momento às articulações rítmicas da sinfonia que têm exatamente a função de escandir? E, no entanto, sabemos bem que a sinfonia não está nem na batuta, nem sobre a estante, e que o gesto de marcar o compasso é incapaz de criálo. ${ }^{30}$

O desejo de localizar as "realidades espirituais" reflete uma atitude reducionista e materialista, que, no caso da música, resultaria da "contaminação" de um modelo visual à esfera sonora. Assim nos revela Jankélévitch na seção "O espelhamento espacial", de La musique et l'ineffable. Segundo o discípulo de Bergson, crer que a música se encontre numa batuta, num instrumento, num disco ou numa notação gráfica, ou seja, num ponto reconhecível para o olho, significaria deslocá-la de seu "território" genuíno, auditivo e temporal.

O deslocamento da música de seu vínculo essencial com a duração também se manifestaria de modo mais concreto, por meio da utilização de certos procedimentos composicionais. Embora este aspecto não seja tratado de modo direto em Bergson, podemos inferi-lo por meio desse estudo e confirmá-lo em La musique et l'ineffable. De acordo com o estudo dedicado à filosofia bergsoniana, a música, em sua semelhança com a vida, possui "eventos que são absolutamente posteriores como o universo de Aristóteles compreende um alto e um baixo" ${ }^{31}$ Inscrito nessa dinâmica, o músico, como outros artistas dedicados à "experiência da narração" ${ }^{32}$, estaria naturalmente consciente da ordem irreversível dos momentos que constituem sua arte.

Constatamos, porém, na história da música composições que, ao manipular séries sonoras explorando-as em diferentes sentidos (retrógrado e invertido), parecem negar tal irreversibilidade. Nestes casos, em que o fim se torna princípio, a música perderia um dos aspectos que permite a Aristóteles - e também ao discípulo de Bergson - relacionar o organismo à obra de arte: a sucessão não-intercambiável "princípio-meio-fim".

Em La musique et l'ineffable, é possível constatar que Jankélévitch não avalia de modo positivo o emprego musical de séries, espelhamentos e motivos reversíveis. A crítica do filósofo a estes procedimentos fundamenta-se no aspecto já mencionado - a desconsideração, por parte dos compositores que os utilizam, da irreversibilidade essencial à música - e a um segundo motivo que a este se soma e se entrelaça. Baseados numa "leitura" analítica, estática, visual e espacial do âmbito sonoro, eles não poderiam ser reconhecidos pela experiência auditiva.

\footnotetext{
30 JANKÉLÉVITCH, V. Bergson. p. 111.

${ }^{31}$ Idem. p. 228.

32 "O biógrafo, o romancista, o músico, possuindo a experiência da narração, sabem que a ordem vital é um fato cujo 'vencimento' é impossível de ser adiado” [Idem. p. 228].
} 
Por tanto, na afirmação "toda a música é noturna" ${ }^{33}$ e crepuscular, também poderia estar implicada a não espacialidade do âmbito sonoro e sua irredutibilidade a um modelo óptico, vinculado a metáforas solares e diurnas, que tendem a desconsiderar, desvalorizar e, até mesmo, suprimir a experiência da duração. Sob esta perspectiva, não só a música, mas todas as "realidades espirituais" - e com elas as experiências fecundas da vida poderiam ser simbolizadas pelo ambiente crepuscular e noturno. Deste modo, a partir de um símbolo diretamente associado à duração (um período do dia), podemos identificar algo de espiritual no "musical" e algo de "musical" no vital.

\section{5) Modo de apreensão da realidade}

A leitura de Bergson permite-nos estabelecer uma aproximação entre arte e vida a partir do modo de apreensão da realidade característico ao artista. Este último encontra-se, segundo Jankélévitch, mais próximo à dinâmica própria da vida, graças a algumas particularidades de sua atividade e da obra à qual se dedica.

A afinidade entre o vital (espiritual) e o artista estabelece-se, sobretudo, graças ao modo com que este experimenta as coisas. Este modo opõe-se ao "olhar" da inteligência, pelo qual nossa civilização costuma considerar a realidade. Consideremos inicialmente este "olhar" predominante, para, em seguida, compreender seu "verso": a "óptica" - ou melhor, a "escuta" - do artista.

O "método da inteligência" examina as coisas segundo uma perspectiva circular, analisando-as à distância, sem incluir-se. No entanto, a neutralidade implica um "ponto de vista": um "olhar" que se coloca fora do observado. Este "fora" possui um duplo significado, quando o examinado é um organismo ou uma "coisa espiritual". Neste caso, a exterioridade do observador não é só espacial, mas também temporal. Aquele que utiliza o método intelectivo simula encontrar-se fora da duração experimentada pelo organismo que analisa. A partir deste ponto de vista supostamente imune à duração, o objeto também aparece como algo congelado, estático.

Portanto, é fácil concluir que o "método da inteligência" se ajusta a uma análise dos mecanismos, coisas naturalmente sem duração e exteriores ao sujeito examinador. Por outro lado, a "neutralidade inumana" ${ }^{34}$ caracte-

33 “(...) pois, enfim, toda a música é noturna, ela, a mais dionisíaca de todas as artes; ela, o lugar dos pensamentos sonhadores, inexprimíveis e crepusculares, o encontro das intuições larvárias no silêncio do logos e na solidão da alma" [JANKÉLÉVITCH, V. Le nocturne. In: La musique et les heures. p. 239].

${ }^{34}$ Idem. p. 228. 
rística a este método não é capaz de aceder à autenticidade da vida. Como seria possível compreender a esfera do espiritual através da eliminação de seu componente mais fundamental: a duração? Uma forma frequentemente utilizada pela intelecção para "contornar" tal dificuldade seria relacionar-se às "coisas espirituais" já concluídas. À primeira vista, poderíamos pensar que estas se encontrariam imunes às possíveis intervenções do tempo, grande adversário de uma inteligência baseada no "ideal de imobilidade" tanto, conceber uma "coisa espiritual", como vimos nos caso da arte interpretativa, como obra acabada e imóvel, implica contradições significativas. Também no caso da vida humana, seria difícil sustentar a possibilidade de uma emoção, de uma ação e de uma existência acabadas, às quais nenhum elemento, novo ou oculto, pudesse somar-se no momento de sua rememoração ou "análise". Deste modo, o suposto estado completo e acabado das "coisas espirituais" não seria mais que uma simulação da inteligência.

É interessante notar que a dificuldade em lidar com o tempo, gerador de instabilidades e contradições, se revela em diferentes áreas do saber e da experiência humana. A proclamação do fim do tempo, feita pelo anjo apocalíptico citado por Jankélévitch ${ }^{36}$, expressa, no plano religioso, um desejo que também se repete em nossa tradição metafísica e epistemológica (que, como o Apocalipse, se serve, curiosamente, de metáforas visuais e lumínicas). O tempo deve ser superado tanto para o homem religioso que almeja vislumbrar a totalidade num só instante, quanto para a inteligência, que "não é feita para compreender o sucessivo e se fecha, de bom grado, no impasse de soluções irreconciliáveis". ${ }^{37}$

A inteligência opera num mundo homogêneo, que não só elimina o sucessivo e a duração, mas também a peculiaridade das coisas. Assim nos comprova a matemática, cujo ideal de uniformização, manifesto na expressão numérica das realidades, traz consigo o ideal de universalidade. Este último, característica fundamental das operações da inteligência, apoia-se numa metafísica que compreende as realidades imanentes não a partir de si mesmas, mas interpretando-as como signos, cópias ou representações de algo externo, isto é, como símbolos ou alegorias de uma essência.

A perspectiva artística opõe-se ao método da inteligência por diferentes motivos. Em primeiro lugar, o artista não "teme" a temporalidade. Esta integra, modifica, torna singulares as "impressões" que inspiram sua obra. No caso das artes interpretativas, a duração é ainda mais necessária, uma vez que constitui a condição de possibilidade de sua própria realização. Vale destacar que, de acordo com o texto Bergson, poderíamos compreen-

\footnotetext{
${ }^{35}$ Idem. p. 24.

${ }^{36}$ Apocalipse 10, 6; JANKÉLÉVITCH, V. Bergson. p. 57.

${ }^{37}$ JANKELLÉVITCH, V. Bergson. p. 48.
} 
der a figura do intérprete como símbolo de uma relação autêntica com o tempo. A ausência de "ponto de vista" que caracteriza o intérprete - mais especificamente o ator, no estudo de Jankélévitch - denota uma profunda imersão no presente, capaz de incluir uma "visão" da totalidade da obra.

Ao contrário do espectador, cuja neutralidade e distanciamento o aproximam à esfera visual e diurna da inteligência, o intérprete é interior ao drama, ao presente, à duração e, de algum modo, interior a si mesmo. Esta interioridade o impede de fragmentar o tempo, conferindo a momentos distintos diferentes valorizações. O intérprete estaria inserido numa espécie de "eterno presente", conceito que expressaria uma possibilidade de conciliação entre a eternidade e a "durée" bergsoniana.

A relação positiva com a temporalidade, característica à perspectiva crepuscular e "auditiva" da arte, implica outras diferenças entre esta e o "método da inteligência". Orientado, ou melhor, submergido na duração que o constitui (e que constitui a obra que compõe ou interpreta), o artista distancia-se das coisas já concluídas. Consequentemente, não procura apreender retrospectivamente uma realidade, uma vez que esta é experimentada como algo ainda em processo.

A ausência de perspectiva daquele que pratica a arte, resultante de sua implicação no mundo que configura e de sua contemporaneidade aos dados que percebe, também indica um "mergulho" no particular. Isto significa um especial envolvimento do artista com os eventos únicos, irrepetíveis e determinados, experimentados na "duração". Segundo o leitor de Bergson, é justamente na singularidade das coisas, e não em seu valor simbólico, conceptual e técnico, que arte descobre a beleza capaz de impulsioná-la (e também, poderíamos completar, muitos dos motivos que tratará e elaborará em suas obras).

A atitude artística distancia-se, assim, do "método da inteligência", orientado por uma concepção de mundo que poderia ser denominada "teoria da miniatura" 38 . Esta, ao considerar as coisas como cópias e buscar uma essência transcendente, acaba por desvalorizar e instrumentalizar as existências singulares. $\mathrm{O}$ "método da inteligência" manifesta-se especialmente em alguns ofícios técnicos, que tendem a converter a realidade em esquemas genéricos e abstratos destinados a fins utilitários.

Vale destacar que o modo de atuar próprio ao artista não constitui tema relevante dentro da estética jankélévitchiana. Como vimos, a experiência do artista ou do intérprete é utilizada para simbolizar um modo de apreensão da realidade que se opõe à ação da "inteligência", contaminada por preconceitos metafísicos e inadequada à esfera do espiritual. Este "mode-

${ }^{38}$ Idem. p. 217. 
lo" consentâneo à vida, simbolizado e, mais que isso, realizado pela arte, corresponderia à atitude filosófica proposta por Bergson.

\section{3) Possiveis distinções entre a esfera orgânica e a obra de arte}

Ao mencionar a imagem do "trabalho-rendimento", na primeira seção deste ensaio, verificamos uma primeira possível distinção entre o organismo e a obra de arte. Esta imagem, extraída de uma observação da dinâmica da produção, revelava-se imprópria ao âmbito da vida. Contudo, esta distinção foi dissolvida quando constatamos que a poiesis específica à arte não poderia ser compreendida, de modo análogo ao organismo, como um processo de "crescimento de ser" (ideia implícita na imagem do "trabalho-rendimento").

Examinemos, agora, outro momento do estudo Bergson que parece sustentar a existência de uma diferença significativa entre o organismo e a obra de arte:

Jamais haveria algo de irracional para um pensamento que, em lugar de comparar de modo insensato, em sua admiração egoísta, os impressos aos manuscritos, os seres vivos às "obras-primas" e a profundidade do céu à pequenez laboriosa de nossa indústria, compreendesse, como diz Pascal, "de cor" o infinito, e se instalasse diretamente no centro das coisas. ${ }^{39}$

Primeiramente, é importante observar que os seres vivos diferem de uma compreensão particular de obra-prima, conforme nos sugere o emprego deste termo entre aspas. Qual seria esta compreensão e de que modo seria interpretada por nosso filósofo?

Seguindo a perspectiva do estudo Bergson, poderíamos concluir que Jankélévitch aqui se refere à acepção de obra de arte predominante para o senso comum, ou seja, pensada como estrutura matéria-forma, produção em geral ou composição de partes. Adotando-se esta compreensão de obraprima, é possível estabelecer certo tipo de conexão/comparação entre arte e vida. Essa aproximação revela-se, porém, inadequada. Vejamos por quê.

Como nos mostra Heidegger, em A origem da obra de arte, nossa civilização teria assimilado, através da teologia cristã e do pensamento grego, uma concepção demiúrgica da criação. Esta fundamentaria a "crença" de que o ser vivo e a obra de arte se compõem de uma estrutura semelhante, constituída da "união" entre matéria e forma. No entanto, tal crença implicaria uma dualidade entre corpo e espírito (vida), entre elementos materiais e

${ }^{39}$ Idem. p. 195. 
formais, que não se aplica nem ao orgânico nem ao artístico. De acordo com Heidegger, a estrutura matéria-forma verifica-se, de fato, nos utensílios (Zeugen) e acaba sendo aplicada impropriamente às meras coisas (entendidas como "entes da natureza") e às obras de arte.

Jankélévitch parece comungar com essa reflexão heideggeriana, que também expressa a "insensatez" de uma aproximação entre seres vivos e obrasprimas a partir de um modelo técnico. De modo similar a Heidegger, um dos motivos para a impropriedade dessa aproximação seria a não dissociação entre matéria e forma na esfera do organismo:

"Ars tractat materiam alienam, natura materiam propriam. Ars circa materiam est, natura vero interior materiæ." (...) A arte gira em torno da matéria - a inteligência, dirá Bergson com eloquência, gira em torno da vida; somente a natureza nesta penetra e se instala. Isto quer dizer que nossa indústria miserável, para alcançar suas "obras-primas", deve impor-se a uma matéria que protesta interiormente contra essa violência. No trabalho de organização, ao contrário, nenhum meio opaco se interpõe entre a obra e o obreiro, ou mais que isso, a operação da vida não se dissocia da própria obra. A distinção entre matéria e forma não possui aqui nenhum sentido, pois a matéria já está toda saturada de forma, como, por sua vez, a forma é ainda, poderíamos dizer, inteiramente carnal. ${ }^{40}$

A comparação feita, nesta passagem, entre arte e vida indicaria uma compreensão dualista da estrutura da obra de arte, relacionada à exterioridade do meio material frente à forma idealizada pelo artista? Se assim for, Jankélévitch se oporia radicalmente à posição de Heidegger, no que concerne à sua compreensão do artístico.

A resposta a esta pergunta não aparece sem contradições no estudo examinado e em outras obras de Jankélévitch. A dualidade entre matéria e forma encontra-se implícita em diferentes momentos da reflexão jankélévitchiana sobre a arte. Esta dualidade manifesta-se, por exemplo, na já mencionada descontinuidade entre a ideia inicial do artista e sua materialização, que subentende uma oposição entre elementos formais e materiais dentro do processo de realização da obra. Em Bergson, esta oposição também é formulada dentro do nível do orgânico, com o objetivo de ilustrar a "resistência" - e, até mesmo, o "risco" - que representa a matéria à realização e afirmação da vida. Nesta perspectiva dualista, que abrange tanto o estético quanto o antropológico, arte e organismo aproximam-se, repetindo o preconceito metafísico e religioso questionado pela filosofia heideggeriana. ${ }^{41}$

${ }^{40}$ Idem. p. 199.

${ }^{41}$ É importante observar que a dualidade atribuída ao organismo (ser humano) na passagem mencionada não se refere à sua "composição" estrutural, à sua "substância", mas sim ao seu processo de realização, ao seu exercício da liberdade. Assim nos confirma Jankélévitch, ao afirmar que “(...) o bergsonismo nos aparece como um monismo da substância, um dualismo da tendência" [Idem. p. 244]. 
Entretanto, esta concepção não deve ser considerada como a predominante no pensamento do filósofo francês. Se retomarmos nossa última citação e a analisarmos com cautela, perceberemos que a "arte" que se distancia da vida não corresponde exatamente ao âmbito das obras de arte (talvez por este motivo, Jankélévitch empregue novamente o termo obras-primas entre aspas). A referida passagem é introduzida por uma máxima de Giordano Bruno, que se utiliza do termo ars em sua acepção clássica, como "fazer técnico" ou como produção em sentido amplo.

Se alterarmos tal compreensão e definirmos arte como "a quintessência do

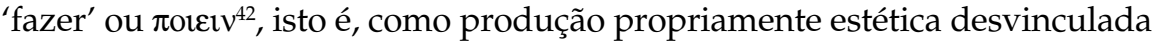
de uma finalidade instrumental ou utilitária, observa-se que a relação entre matéria e forma se converte em outro aspecto capaz de aproximar o organismo à obra de arte. No entanto, esta aproximação não ocorre do mesmo modo como é pensada pelo senso comum. Para este, a dissociação matéria e forma é, como observamos, o elemento que garante uma semelhança entre a obra de arte e o organismo, uma vez que também no âmbito da vida se pensaria uma dissociação entre corpo e espírito. Por outro lado, para o leitor de Bergson, é a continuidade entre matéria e forma o fator que permite tal aproximação, que se torna possível quando o âmbito artístico é diferenciado da produção utilitária ou mecânica (relacionada à produção de utensílios tratada por Heidegger):

Numa máquina, função e matéria coabitam, por assim dizer, sem se simpatizarem; nos organismos, a função é uma sequência íntima e necessária da estrutura. É por isso que se deve dizer que um mecanismo funciona e um organismo opera. Daí essa suavidade espiritual, essa beleza inimitável da vida e das obras que imitam a vida. ${ }^{43}$

Assim como ocorreu em relação à imagem do "trabalho-rendimento", outra possível distinção entre o organismo e a obra de arte dissolve-se no momento em que o conceito do artístico se especifica. ${ }^{44}$ Deste modo, poderíamos concluir que Jankélévitch, ao considerar insensata a comparação entre seres vivos e "obras-primas", não invalida tal aproximação. Se esta se revela imprecisa dentro da concepção predominante de organismo e de obra de arte, ela pode estabelecer-se a partir de outros pontos de contato, descobertos quando a compreensão dos fenômenos em questão é reformulada.

\footnotetext{
${ }^{42}$ JANKÉLÉVITCH, V. Le je-ne-sais-quoi et le presque-rien. v. I. La manière et l'occasion. p. 51 .

43 JANKÉLÉVITCH, V. Bergson. p. 200.

${ }^{44}$ A imagem do "trabalho-rendimento" encontra-se associada à distinção matéria e forma. A obra que experimenta um "aumento de ser" não deixa de ser aquela que, a fim de ser completa, deve receber um incremento de matéria, ao contrário do organismo e de certo tipo de obra de arte, que já "nasceriam inteiros". Por esta razão, um mesmo motivo - a especificação da compreensão de arte - é capaz de revelar a inaplicabilidade tanto da imagem do "trabalho-rendimento" quanto da estrutura matéria e forma ao âmbito do propriamente artístico.
} 
Além do tema do "trabalho-rendimento" e da estrutura hilemórfica, examinemos agora três outras possíveis distinções entre o organismo e a obra de arte. A primeira delas refere-se às diferentes "condutas" que caracterizam seus modos de "operação". Segundo Jankélévitch, a natureza difere das criações humanas por "operar" de modo simples e inconsciente:

A natureza realiza os organismos sem saber anatomia, como o impressor executa instantaneamente obras-primas sem ser calígrafo, ou, se preferirmos, como o cristal de neve adquire de uma só vez a simetria perfeita de sua figura sem recorrer ao esquadro nem ao compasso. E, assim, é a simplicidade que, nas coisas vitais, é verdadeiramente essencial e primitiva. ${ }^{45}$

No entanto, também neste aspecto é possível detectar alguma ambiguidade. A passagem que acabamos de citar contrasta a natureza com atividades mais técnicas que artísticas. Quando nos transferimos à esfera da arte propriamente dita, ou seja, como "quintessência do fazer", parece possível identificar a "atitude" da natureza com a "atitude" do artista: "A natureza, diz Schopenhauer, é ingênua como o gênio". ${ }^{46}$

A pesar de seu tom romântico, esta afirmação do filósofo alemão figura na obra à qual nos dedicamos por se encontrar em ressonância com a perspectiva bergsoniana. Em diferentes momentos da obra, Jankélévitch faz referência a alguma ideias formuladas por Schopenhauer e compartilhadas por Bergson. Além do tema do amor, já citado neste ensaio, ambos os filósofos estão de acordo quanto a um quarto aspecto que distinguiria arte e natureza. Segundo eles, esta última caracteriza-se por certa incompreensibilidade, que se manifesta notoriamente na eliminação repentina e brutal dos organismos. Frente à destruição ininteligível das espécies, biomas, planetas e estrelas, constatamos que a relação entre o artista e a sua obra não poderia ser aplicada à relação entre a natureza e "seu" organismo.

O zelo da humanidade por suas produções artísticas opõe-se à "indiferença" da natureza por "suas" espécies em virtude dos distintos processos pelos quais a obra e o organismo se constituem. A eliminação brusca dos animais que tanto nos choca apresenta uma relação com a "produção" também repentina (imediata) dos organismos. Assim, este tema nos conduz, como na primeira seção deste ensaio, a conceber uma diferença entre arte e vida a partir dos distintos modos de geração que as caracterizam.

Uma quinta e última oposição entre o organismo e a obra de arte residiria na configuração essencial do primeiro, na qual nada há de supérfluo ou de meramente ornamental:

${ }^{45}$ Idem. p. 198.

${ }^{46}$ Idem. p. 201. 
Não há, ao contrário, nada de "proposital" nas obras da vida; nem ornamento nem coisa ornada; suas combinações são sempre as únicas possíveis, porque sua matéria exprime diretamente a essência mesma do indivíduo vivo. ${ }^{47}$

No contexto desta passagem, a esfera da vida contrasta nitidamente com as realidades materiais representadas pelos mecanismos. Nestes, verificarse-ia, além da dissociação entre matéria e função, a exterioridade de seus eventuais ornamentos em relação à sua estrutura básica. No entanto, esta tese permite o estabelecimento de uma distinção não apenas entre organismos e mecanismos, mas também entre os primeiros e algumas obras de arte. Recordemos, no âmbito musical, a liberdade de ornamentação em obras barrocas, assim como as cadências de concerto, que podem ser compreendidas como grandes ornamentos, passíveis de supressão ou de substituição.

No entanto, também no que toca este aspecto, encontramos uma ambiguidade. Ao referir-se às "obras da vida", Jankélévitch parece não se limitar aos organismos, mas sim incluir as "obras que imitam a vida", mencionadas poucas linhas antes da passagem citada. Se assim for, e por "obras da vida" compreendermos as "coisas espirituais" em geral, poderiam existir, novamente dentro da arte musical, composições cujos ornamentos figurariam como elementos constitutivos, inseparáveis de sua própria estrutura. No entanto, é importante destacar a dificuldade em se estabelecer, de modo concreto, quando uma ornamentação seria intrínseca a uma obra ou apenas um adereço supérfluo. Além de este tema não ser abordado por Jankélévitch - trata-se apenas de uma especulação que realizamos, motivada pela menção feita pelo filósofo ao ornamento mecânico ou vital -, a tentativa de efetuar tal distinção poderia incorrer numa estética de caráter normativo.

De qualquer modo, não deixa de ser curioso observar que o barroco musical seja pouquíssimas vezes explorado pelo discípulo de Bergson. Esta omissão e até mesmo a "insensibilidade" confessada por Jankélévitch em relação ao grande mestre do barroco, J. S. Bach ${ }^{48}$, poderia estar motivada pelo emprego, naquele estilo de época, de procedimentos "estranhos" à vida, tais como a repetição idêntica de seções - contrária à irreversibilidade dos eventos vitais (como ocorre em muitas das sonatas e suítes barrocas) - e a utilização recorrente de ornamentos, considerados como extrínsecos às obras?

Diante da dúvida frente à valorização jankélévitchiana da ornamentação musical, poderíamos concluir esta seção afirmando que, de todos os aspectos extraídos do estudo Bergson, somente o quarto (a incompreensibilidade

\footnotetext{
${ }^{47}$ JANKÉLÉVITCH, V. Bergson. p. 200.

48 JANKÉLÉVITCH, V. Quelque part dans l'inachevé. p. 255.
} 
da natureza ao gerar ou eliminar os seres vivos de modo brutal ou repentino) constitui uma diferença inequívoca entre a esfera orgânica e a artística.

\section{4) Conclusão}

A música não é uma caligrafia projetada no espaço, mas sim uma experiência vivida análoga à vida. ${ }^{49}$

Uma mesma pergunta poderia ser suscitada em diferentes momentos deste ensaio: a obra de arte - especialmente a música - é essencialmente análoga à vida ou esta analogia é estabelecida a posteriori, como um projeto para a arte e o artista? Desde a introdução deste trabalho, esta dúvida esteve presente. $\mathrm{O}$ vínculo entre a obra de arte e o organismo aparece, já na Poética, não em termos de identidade, mas como um "dever" (a narrativa mimética "deve ser composta", "deve possuir", "deve ser").

Em Bergson, a vida também aparece como um "modelo" para a arte: um modelo a ser seguido, a ser imitado. Em duas passagens do estudo, citados neste trabalho, Jankélévitch refere-se ao desejo da arte (ou do artista) de "imitar" os aspectos centrais da vida. ${ }^{50}$ Se esta deve ser imitada pela arte, o vínculo entre ambas as esferas não poderia ser algo natural, constitutivo.

Esta ideia parece confirmar-se pela distinção estabelecida entre os textos materiais e espirituais, que representam, retrospectivamente, o mecânico e o vital. Se um mesmo meio - o discurso verbal - é capaz de identificar-se, em diferentes circunstâncias, com estas duas esferas opostas, algo nele deve favorecer a aproximação ou o afastamento em relação à vida. Embora Jankélévitch assinale, em diferentes obras, a impossibilidade de determinar o "lugar" do espiritual e do encantamento (charme), a estética musical deste autor "localiza" alguns procedimentos que impediriam uma aproximação à vida e, com ela, uma "realização" do artístico. Dentre estes, destacamos a utilização e manipulação de séries sonoras, a aplicação de um modelo visual ao musical, a inscrição numa estrutura formal preestabelecida (dotada de previsibilidade) e, provavelmente, o emprego de ornamentações "supérfluas".

${ }^{49}$ JANKÉLÉVITCH, V. La musique et l'ineffable. p. 118.

50 1) "Essa imanência mútua, da qual nosso entendimento tem horror, nossas artes procuram, ao contrário, imitar (...)" [JANKÉLÉVITCH, V. Bergson. p. 6]; 2) "Daí essa suavidade espiritual, essa beleza inimitável da vida e das obras que imitam a vida" [Idem. p. 200]. 
Deste modo, a suposta correspondência entre arte e vida poderia justificar um preconceito (e também uma desconsideração) frente a algumas obras nas quais se identificam os procedimentos citados. Por outro lado, apoiaria uma estética que restringe seu campo de reflexão a algumas composições e poéticas nas quais se verificam alguns "traços" considerados como fundamentais à vida.

Além disso, esta compreensão "orgânica" do artístico implica uma hierarquia entre as artes. Nesta, a supremacia é conferida à "expressão" que mais se aproxima aos atributos vitais, nos quais se manifesta a inefabilidade. Nas passagens do estudo Bergson examinadas, assim como em outros momentos do corpus jankélévitchiano, a arte sonora é, sem dúvida, aquela que apresenta uma maior semelhança com o organismo e com a experiência humana da vida. Talvez seja este um dos motivos pelo qual a música ocupa, sobre as demais artes, um lugar de destaque no pensamento de nosso autor.

A supremacia estética - e também ontológica - da arte musical, inefável por excelência, revela uma valorização do encanto (charme) sobre a beleza, do sonoro sobre o óptico, do noturno sobre o diurno, do movimento contínuo e inapreensível sobre a harmonia estática e numérica. No entanto, a música também pode representar o polo da exatidão, da ciência e da matemática, quando pensada de modo teórico e dissociada de uma realização artística particular e temporal. Em Bergson, Jankélévitch demonstra estar consciente deste inegável aspecto do musical, ${ }^{51}$ observado desde o pitagorismo e explorado em diferentes momentos da história da filosofia.

Portanto, poderíamos pensar que a aproximação entre música (arte) e vida, além de justificar uma estética normativa em que determinadas poéticas, estilos e "expressões" artísticas se revelam mais "autênticas" que outras, implica um segundo problema. Para que esta aproximação se estabeleça, torna-se necessário delimitar a compreensão do musical, do artístico e talvez também do vital.

Esta faceta um tanto artificial ou preconceituosa da aproximação entre a esfera da arte e da vida é constatada especialmente quando elaborada a partir do eixo da obra. No entanto, se a considerarmos a partir do ser humano que se relaciona com a vida e com a arte - seja ele o compositor, o intérprete ou o receptor -, o vital e o artístico entrelaçam-se de modo intrínseco. A fim de realizar, recriar ou apreciar uma obra, devemos "mergulhar" no presente e na "interioridade" do que percebemos. Assim como, para experimentar a vida, devemos ser "contemporâneos" ao nosso drama. Neste ponto significativo, ressaltado por Jankélévitch em seu estudo Bergson, arte e vida identificam-se graças a um projeto comum.

\footnotetext{
${ }^{51}$ Cf. JANKÉLÉVITCH, V. Bergson. p. 113.
} 


\section{Bibliografia}

ARISTÓTELES. Poética. Tradução, comentários e índices analítico e onomástico Eudoro de Souza. In: Os pensadores. Aristóteles (II). São Paulo: Abril Cultural, 1984.

JANKÉLÉVITCH, Vladimir. Bergson. Paris: Félix Alcan, 1931.

La musique et les heures. Paris: Seuil, 1988.

. La musique et l'ineffable. Paris: Seuil, 1983.

. Le Je-ne-sais-quoi et le presque-rien. Paris: Seuil, 1980.

JANKÉLÉVITCH, Vladimir e BERLOWITZ, Béatrice. Quelque part dans l'inachevé. Paris: Gallimard, 1978.

HEIDEGGER, Martin. El origen de la obra de arte. Tradução Helena Cortés e Arturo Leyte. In: HEIDEGGER, Martin. Caminos de bosque. Madrid: Alianza, 1996.

http://www.heideggeriana.com.ar/textos/origen_obra_arte.htm

LEIBNIZ, G. W. La monadología. Tradução, introdução e notas Virginia Naughton. Buenos Aires: Quadrata, 2005.

SCHOPENHAUER, Arthur. O mundo como vontade e representação. Tradução M. F. Sá Correia. Rio de Janeiro: Contraponto, 2001.

Endereço do Autor:

Rua do Mosteiro, 105, Apto. 501

30380-780 Belo Horizonte - MG

e-mail: clovisalgon@terra.com.br 